\title{
Household Density among Undocumented Mexican Immigrants in New York City
}

\author{
Katherine Standish · Vijay Nandi · Danielle C. Ompad • \\ Sandra Momper · Sandro Galea
}

(C) Springer Science+Business Media, LLC 2008

\begin{abstract}
Background High household density increases exposure to communicable diseases, psychological distress in adults, and poor long-term health in children. High residential density, which may be a mediator of poor health, is common among immigrants. Methods We used data from a pilot survey among Mexican immigrants in New York City. Respondents were recruited through venue-based sampling in neighborhoods with large Mexican populations. Results Among respondents that reported
\end{abstract}

K. Standish · V. Nandi · D. C. Ompad · S. Galea Center for Urban Epidemiologic Studies, New York Academy of Medicine, 1216 Fifth Avenue, 5th Floor, New York, NY 10029, USA

K. Standish

e-mail: kstandish@nyam.org

V. Nandi

e-mail: vnandi@nyam.org

D. C. Ompad

e-mail: dompad@nyam.org

S. Momper

University of Michigan School of Social Work, Ann Arbor, MI, USA

e-mail: smomper@umich.edu

S. Galea $(\bowtie)$

Department of Epidemiology, University of Michigan School of Public Health, 109 Observatory St, Room 3663, Ann Arbor, MI 48109-2029, USA

e-mail: sgalea@umich.edu

S. Galea

Columbia University Mailman School of Public Health,

New York, NY, USA being undocumented $(N=404)$, the mean number of people per room (PPR) of residence was 2.2. In multivariate analyses, living in conditions of $>2$ PPR was positively associated with living with one's children ( $\mathrm{OR}=2.3,95 \%$ $\mathrm{CI}=1.4-3.9)$, having experienced food insecurity in the past 6 months $(\mathrm{OR}=2.0,95 \% \mathrm{CI}=1.1-3.6)$, and language discrimination $(\mathrm{OR}=2.3$ compared to other forms of discrimination, $95 \% \quad \mathrm{CI}=1.2-4.4)$. Conclusions Undocumented Mexican immigrants, particularly those who are linguistically marginalized and experience food insufficiency, live in conditions of marked household density in NYC.

Keywords Undocumented immigrants · Mexicans ·

Housing · High residential density .

Economically marginalized

\section{Background}

The deleterious health effects of housing conditions-e.g., mold, pest infestation, unsafe drinking water, asbestoshave been well documented [1-3]. The health effects of high household density-defined as the number of occupants per room or square foot-are much less clear. While studies have found associations between high household density and negative health outcomes [4-8], the causal relationship is highly debated and other studies have shown low household density may not be associated with positive health outcomes [9-11].

Foreign-born and minority residents of the U.S. experience markedly denser and poorer housing conditions than native-born residents [12-14]. In New York City (NYC), foreign-born residents are more likely than native-born to live in denser conditions, in structures of 
poorer quality with maintenance deficiencies, and to contribute a larger proportion of household income to housing costs. In particular, immigrants who live with children under age 18 and other unrelated individuals, have less than a high school education, and receive public assistance, are more likely to live in conditions of high household density and poorer quality housing [12]. In another analysis, it was shown that the foreign-born, particularly Hispanic, Asian, and more recent immigrants were more likely to be living in crowded conditions than other groups [10].

The foreign-born, among whom housing conditions have consistently been worse, have also increased in population-by 57\% between 1990 and 2000 [15]. The number of undocumented persons entering the United States has overtaken the number entering legally [16] and Mexicans make up the largest proportion of both groups: in 2005 Mexicans accounted for $56 \%$ of the estimated 11.1 million undocumented persons living in the United States [17]. In 2006, NYC was home to 3 million foreignborn residents, of which an estimated 169,500 were from Mexico [18], representing a growth of $275 \%$ between 1990 and 2000 [19]. Unofficial estimates of the actual size of the NYC Mexican population suggest that the real number may have been closer to 300,000 in 2000. Like Mexicans in other parts of the United States, a substantial portion of Mexicans in NYC are believed to be undocumented [20]. Meanwhile, newly arrived immigrants to NYC face one of the least affordable housing markets in the United States, with among the lowest vacancy rates and highest housing costs in the nation [21, 22]. This may put the expanding population of undocumented Mexican immigrants at particular disadvantage with regard to housing options, and at risk of health problems associated with poor housing.

To date, little has been reported on the health or living conditions of the quickly expanding Mexican-born population in NYC. In this paper, we begin to fill this gap by describing household density and its correlates among a sample of undocumented Mexicans in NYC.

\section{Methods}

Sample

The sampling frame consisted of adults (aged 18 years or older) from all five boroughs of NYC who reported being born in Mexico. Participants were recruited from 12 communities with large populations of Mexican immigrants according to the U.S. Census, as described previously [23]. The neighborhoods selected were: the South Bronx, Chelsea, East Harlem, the Lower East Side,
Astoria, Elmhurst, Jackson Heights, North Corona, Bushwick, Sunset Park, Williamsburg, and Port Richmond.

Outreach workers, trained in the data collection requirements of the study, recruited potential participants between October 2004 and December 2004 using street outreach techniques common in research involving immigrant populations [24-26] and other hard-to-reach populations [27, 28]. Outreach workers positioned at preidentified venues with heavy foot traffic solicited participation by distributing fliers and engaging people in conversations about the objectives, inclusion criteria, and the voluntary nature of the study. Participants qualified for the study if they reported being 18 years of age or older, were born in Mexico, and were currently living in NYC. Interviews were conducted in English or Spanish by trained, supervised interviewers. The Institutional Review Board at the New York Academy of Medicine and the University Committee on Activities Involving Human Subjects at New York University approved the study and all study subjects provided oral consent at the time of the interview. In order to preserve participants' anonymity, no personal identifiers (e.g., name, address, etc.) were collected from participants.

\section{Measures}

We asked about demographic characteristics, including age, gender, marital status, level of education, and number of children. Respondents were asked about their legal status in the United States and the year they entered the U.S. Respondents reported the total income earned in the formal economy (i.e., "on the books" income where taxes are taken out, including public assistance) and in the informal economy (i.e., "off the books" income on which taxes were not paid). We also asked respondents if they had worked as day laborers, had been homeless, and how much money they sent to family or friends in Mexico.

Household density was determined by the number of adults and minors who lived in the same house, apartment, or rented room where the respondent had slept most of the time in the past 6 months, and the number of rooms in that apartment or house (excluding bathrooms). We calculated mean people per room (PPR) and the prevalence of greater than one PPR and two PPR (the median in this simple). In the U.S. standards for "crowding" and "severe crowding" set by the federal government have decreased over the past century as household density itself has decreased, and are currently 1 PPR and 1.5 PPR, respectively [10, 29]. However, there exists great variability in measures and standards among researchers and housing authorities even within the United States [9, 29]. A higher cut-off may help identify households with more severe housing problems [9, 10]. We therefore chose 2 PPR as a cut-off based on the 
high level of household density among Hispanic immigrants and the high median PPR in our sample (2 PPR). A lower cut-off (e.g., 1 or 1.5 PPR) would lump those in moderately dense conditions with those in very dense conditions. In addition to PPR, we asked respondents if the house or apartment where they slept most of the time was their own, a parent's, a spouse's or someone else's.

We assessed respondents' health status by asking about the number of days that poor physical or mental health limited usual activities in the past 30 days [30-32]; health status responses ranged from zero, $1-5$, or greater than 5 days of poor physical or mental health. We also asked respondents if they were covered by any health insurance during the past 6 months.

We defined food insufficiency as periods of time when respondents experienced hunger but were unable to afford food. Food insufficiency was measured with a single item, and respondents were asked whether they had experienced periods in the last 6 months when they were hungry, but were unable to eat because they could not afford enough food. Although there is substantial debate in the literature over how to best measure food insecurity and hunger [33, 34], several studies have shown that single item measures of food insufficiency are predictive of dietary, mental, and physical health outcomes [34-37].

We assessed levels of acculturation using a modified version of the Welfare Reform Baseline Interview acculturation module, based on a scale developed for use among Hispanic populations [38]. Linguistic acculturation was assessed using a seven-item scale that asked about the preference for other languages as compared to English in a variety of contexts. We assessed social acculturation using a four-item scale that asked about preference for Mexican, Latino, or Hispanic groups as compared to other groups in a variety of social contexts. The combined acculturation scores were summed and divided into tertiles for analysis. To evaluate social support we asked about emotional support (e.g., "someone to love you and make you feel wanted"), instrumental support (e.g., someone to help you if you were confined to bed"), and appraisal support (e.g., "someone to give you good advice in a crisis") in the past 6 months [39]. We summed responses and divided the combined social support score into tertiles for analysis. Respondents were asked if they had ever been discriminated against, prevented from doing something, or been hassled or made to feel inferior because of age, race, language, immigrant status, sex, sexual orientation, poverty, drug use, having been in jail or prison, religion, mental illness, physical illness or disability, or other reason. We asked respondents to identify the form of discrimination that impacted their life the most and categorized this as either "none" or discrimination relating to race, language, immigrant status, or other.
Statistical Analyses

We calculated the prevalence of more than 2 PPR among participants who reported being undocumented. Bivariate associations were examined for categorical variables using chi-square tests of association, and where chi-square tests were not valid, Fisher's exact test was used. The reference group in bivariate analysis was those participants that reported living in conditions of $\leq 2 \mathrm{PPR}$. Variables that were significant at the $P \leq 0.1$ level in the bivariate analysis were included in multivariable stepwise logistic regression: gender, education, number of children, if children are living with subject, number of days poor physical or mental health limited activities in past 30 days, food insufficiency in the past 6 months, total number of adults and minors in household, where subject lives most of the time, level of linguistic acculturation/preference, level of social acculturation/preference, form of discrimination that most impacted life, and having problems because foreign born in past 6 months. Variables were retained in the final stepwise model if they were significant at the $P \leq 0.05$ level, using Wald $P$-values. We performed all analyses using SAS version 8.2 [40].

\section{Sample Characteristics}

We recruited 505 persons for this study. Of the 445 participants with household density data, 9.2\% reported documented migration status. Among documented subjects, $26.8 \%$ lived in conditions of $>2$ PPR, compared to $37.6 \%$ of undocumented subjects. Documented status was not found to be significant in predicting household density in bivariate or multivariate analysis. We, therefore, restricted analyses for this study to the 404 respondents who were undocumented immigrants and lived in a house, apartment or rented room. Table 1 details the sample characteristics. The median age was 30 years $(\mathrm{IQR}=25$ 38 ), $29.6 \%$ of respondents were female, $51.2 \%$ of respondents were married, and $67.3 \%$ of the sample had at least one child. Approximately $83 \%$ of respondents had not completed high school. Median years living in the United States were $5(\mathrm{IQR}=3-10)$. The formal economy was a source of income for only $32.3 \%$ of respondents over the past year, while the informal economy was an income source for $66.8 \%$, and $23.3 \%$ of respondents reported working as day laborers in the past 6 months. Remittances were sent to family or friends in Mexico by $85.9 \%$ of respondents, sending a median amount of US\$ 400 per month (IQR $=200-800)$.

Household density was high, with $82.5 \%$ living with more than 1 PPR, $37.6 \%$ living with more than 2 PPR, and $27.7 \%$ living with six other people (adults and children) or more (Table 2). In terms of health, $10.4 \%$ of respondents reported that poor physical or mental health limited their 
Table 1 Socio-demographic characteristics by people per room $(N=404)$

\begin{tabular}{|c|c|c|c|c|c|c|c|}
\hline & \multicolumn{2}{|l|}{ Total } & \multicolumn{2}{|c|}{$>2$ People per room } & \multicolumn{2}{|c|}{$\leq 2$ People per room } & \multirow[t]{2}{*}{$P$-value } \\
\hline & $\begin{array}{l}N \\
404\end{array}$ & Percent & $\begin{array}{l}N \\
152\end{array}$ & $\begin{array}{l}\text { Percent } \\
37.6\end{array}$ & $\begin{array}{l}N \\
252\end{array}$ & $\begin{array}{l}\text { Percent } \\
62.4\end{array}$ & \\
\hline Gender & & & & & & & 0.04 \\
\hline Male & 283 & 70.4 & 98 & 34.6 & 185 & 65.4 & \\
\hline Female & 119 & 29.6 & 54 & 45.4 & 65 & 54.6 & \\
\hline Median age (interquartile range) & 30 & $(25-38)$ & 30 & $(25-38)$ & 30 & $(24-38)$ & 0.8 \\
\hline Education (highest level completed) & & & & & & & 0.04 \\
\hline Less than high school & 334 & 82.7 & 128 & 38.3 & 206 & 61.7 & \\
\hline High school or GED & 41 & 10.2 & 19 & 46.3 & 22 & 53.7 & \\
\hline At least some college & 29 & 7.2 & 5 & 17.2 & 24 & 82.8 & \\
\hline Marital status & & & & & & & 0.2 \\
\hline Single & 163 & 40.4 & 55 & 33.7 & 108 & 66.3 & \\
\hline Married & 207 & 51.2 & 86 & 41.6 & 121 & 58.5 & \\
\hline Divorced, separated, widowed, other & 34 & 8.4 & 11 & 32.4 & 23 & 67.7 & \\
\hline Children & & & & & & & $<0.01$ \\
\hline None & 131 & 32.7 & 34 & 26 & 97 & 74.1 & \\
\hline 1 & 63 & 15.7 & 28 & 44.4 & 35 & 55.6 & \\
\hline 2 & 90 & 22.4 & 30 & 33.3 & 60 & 66.7 & \\
\hline 3 & 59 & 14.7 & 29 & 49.2 & 30 & 50.9 & \\
\hline$>3$ & 58 & 14.5 & 30 & 51.7 & 28 & 48.3 & \\
\hline Children living with subject & & & & & & & 0.02 \\
\hline No & 135 & 49.8 & 49 & 36.3 & 86 & 63.7 & \\
\hline Yes & 136 & 50.2 & 68 & 50 & 68 & 50 & \\
\hline Median years in US (interquartile range) & 5 & $(3-10)$ & 5 & $(2-9)$ & 5 & $(3-10)$ & 0.4 \\
\hline Homeless in last 6 months & & & & & & & 0.7 \\
\hline No & 34 & 70.8 & 15 & 44.1 & 19 & 55.9 & \\
\hline Yes & 14 & 29.2 & 7 & 50 & 7 & 50 & \\
\hline Ever homeless & & & & & & & 0.2 \\
\hline No & 354 & 87.6 & 129 & 36.4 & 225 & 63.6 & \\
\hline Yes & 50 & 12.4 & 23 & 46 & 27 & 54 & \\
\hline Legal income & & & & & & & 0.1 \\
\hline No legal income & 236 & 67.8 & 96 & 40.7 & 140 & 59.3 & \\
\hline Any legal income & 112 & 32.3 & 36 & 32.1 & 76 & 67.9 & \\
\hline "Off the books" income & & & & & & & 0.7 \\
\hline No "off the books" income & 107 & 33.2 & 41 & 38.3 & 66 & 61.7 & \\
\hline Any "off the books income" & 215 & 66.8 & 87 & 40.5 & 128 & 59.5 & \\
\hline Day labor & & & & & & & 0.9 \\
\hline No & 310 & 76.7 & 116 & 37.4 & 194 & 62.6 & \\
\hline Yes & 94 & 23.3 & 36 & 38.3 & 58 & 61.7 & \\
\hline Remitted money to home country & & & & & & & 0.4 \\
\hline No & 57 & 14.1 & 24 & 42.1 & 33 & 57.9 & \\
\hline Yes & 346 & 85.9 & 127 & 36.7 & 219 & 63.3 & \\
\hline Median $\$$ remitted monthly (interquartile range) & 400 & $(200-800)$ & 400 & $(200-680)$ & 400 & $(200-800)$ & \\
\hline
\end{tabular}

usual activities for at least six of the past 30 days. Only $11 \%$ had access to health insurance in the previous 6 months and $28.8 \%$ reported food insufficiency in those same 6 months (Table 2). Some form of discrimination was reported by $61 \%$ of respondents. The most frequently reported form of discrimination that most affected their life was language $(25.6 \%)$, followed by immigrant status $(16.5 \%)$, race (13.2), and other $(5.8 \%)$ (Table 3$)$. 
Table 2 Reported health and housing by people per room $(N=404)$

\begin{tabular}{|c|c|c|c|c|c|c|c|}
\hline & \multicolumn{2}{|c|}{ Total } & \multicolumn{2}{|c|}{$>2$ People per room } & \multicolumn{2}{|c|}{$\leq 2$ People per room } & \multirow[t]{2}{*}{$P$-value } \\
\hline & $\begin{array}{l}N \\
404\end{array}$ & Percent & $\begin{array}{l}N \\
152\end{array}$ & $\begin{array}{l}\text { Percent } \\
37.6\end{array}$ & $\begin{array}{l}N \\
252\end{array}$ & $\begin{array}{l}\text { Percent } \\
62.4\end{array}$ & \\
\hline \multicolumn{7}{|l|}{ Days physical health not good in past 30 days } & 0.6 \\
\hline 0 days & 235 & 59.1 & 89 & 37.9 & 146 & 62.1 & \\
\hline $1-5$ days & 97 & 24.4 & 34 & 35.1 & 63 & 65 & \\
\hline$>5$ days & 66 & 16.6 & 28 & 42.4 & 38 & 57.6 & \\
\hline \multicolumn{7}{|l|}{ Days mental health not good in past 30 days } & 0.5 \\
\hline 0 days & 210 & 52.9 & 83 & 39.5 & 127 & 60.5 & \\
\hline $1-5$ days & 113 & 28.5 & 37 & 32.7 & 76 & 67.3 & \\
\hline$>5$ days & 74 & 18.6 & 29 & 39.2 & 45 & 60.8 & \\
\hline \multicolumn{7}{|c|}{ Days poor physical or mental health limited activities in past 30 days } & 0.08 \\
\hline 0 days & 312 & 78.8 & 115 & 36.9 & 197 & 63.1 & \\
\hline $1-5$ days & 43 & 10.9 & 12 & 27.9 & 31 & 72.1 & \\
\hline$>5$ days & 41 & 10.4 & 21 & 51.2 & 20 & 48.8 & \\
\hline \multicolumn{7}{|l|}{ Health insurance coverage last 6 months } & 0.4 \\
\hline No & 357 & 89 & 131 & 36.7 & 226 & 63.3 & \\
\hline Yes & 44 & 11 & 19 & 43.2 & 25 & 56.8 & \\
\hline \multicolumn{7}{|l|}{ Food insufficiency in last 6 months } & 0.06 \\
\hline No & 287 & 71.2 & 100 & 34.8 & 187 & 65.2 & \\
\hline Yes & 116 & 28.8 & 52 & 44.8 & 64 & 55.2 & \\
\hline \multicolumn{7}{|l|}{ Total adults and children living in household } & $<0.01$ \\
\hline $1-2$ & 40 & 9.9 & 0 & 0 & 40 & 100 & \\
\hline 3 & 38 & 9.4 & 6 & 15.8 & 32 & 84.2 & \\
\hline 4 & 83 & 20.5 & 11 & 13.3 & 72 & 86.8 & \\
\hline 5 & 75 & 18.6 & 31 & 41.3 & 44 & 58.7 & \\
\hline 6 & 56 & 13.9 & 16 & 28.6 & 40 & 71.4 & \\
\hline$>6$ & 112 & 27.7 & 88 & 78.6 & 24 & 21.4 & \\
\hline \multicolumn{7}{|l|}{ Where do you live most of the time? } & 0.02 \\
\hline Someone else's house/apt & 115 & 28.5 & 54 & 47 & 61 & 53 & \\
\hline Own, parent's, spouse's, or rented room & 289 & 71.5 & 98 & 33.9 & 191 & 66.1 & \\
\hline
\end{tabular}

\section{Bivariate Analyses}

In bivariate analyses women $(P=0.04$, Table 1$)$, those with a high school education or less $(P=0.04)$, those with more children $(P<0.01)$ and those living with their own children $(P=0.02)$ were more likely to report living in households with more than 2 PPR. As seen in Table 2, higher household density was reported by those who had experienced food insufficiency in the past 6 months $(P=0.06)$, and by those whose physical or mental health had limited their activities for at least 6 days in the past 30 days $(P=0.08)$. Respondents living in someone else's house or apartment were more likely to report more than 2 PPR compared to those living in a spouse's, parent's, one's own home, or in a rented room $(P=0.02)$. Not surprisingly, households with greater numbers of both adults and minors were more likely to have more PPR $(P<0.01)$.
Lower levels of both linguistic $(P=0.01$, Table 3$)$ and social $(P=0.03)$ acculturation were associated with higher household density, as were language discrimination as the form of discrimination that most impacted life $(P=0.02)$ and problems related to being foreign-born $(P=0.08)$.

\section{Multivariate Analyses}

In the multivariate model (Table 4), living with more than 2 PPR was associated with living with one's own children $(\mathrm{OR}=2.3,95 \% \mathrm{CI}=1.4-3.9)$, experiencing food insufficiency in the past 6 months $(\mathrm{OR}=2.0,95 \% \mathrm{CI}=1.1$ 3.6), and language discrimination as the form of discrimination that most impacted one's life ( $\mathrm{OR}=2.3$ compared to discrimination based on race, immigrant status and other forms, $95 \% \mathrm{CI}=1.2-4.4$ ). 
Table 3 Acculturation, social support, and discrimination by people per room $(N=404)$

\begin{tabular}{|c|c|c|c|c|c|c|c|}
\hline & \multicolumn{2}{|c|}{ Total } & \multicolumn{2}{|c|}{$>2$ People per room } & \multicolumn{2}{|c|}{$\leq 2$ People per room } & \multirow[t]{2}{*}{$P$-value } \\
\hline & $N$ & Percent & $N$ & Percent & $N$ & Percent & \\
\hline \multicolumn{7}{|c|}{ Linguistic acculturation/preference } & 0.01 \\
\hline Lowest level & 93 & 25.2 & 47 & 50.5 & 46 & 49.5 & \\
\hline Moderate level & 117 & 31.7 & 46 & 39.3 & 71 & 60.7 & \\
\hline Highest level & 159 & 43.1 & 50 & 31.5 & 109 & 68.6 & \\
\hline \multicolumn{7}{|l|}{ Social acculturation/preference } & 0.03 \\
\hline Lowest level & 160 & 43.2 & 74 & 46.3 & 86 & 53.8 & \\
\hline Moderate level & 103 & 27.8 & 33 & 32 & 70 & 68 & \\
\hline Highest level & 107 & 28.9 & 36 & 33.6 & 71 & 66.4 & \\
\hline \multicolumn{7}{|l|}{ Social Support } & 0.5 \\
\hline Low & 170 & 44 & 68 & 40 & 102 & 60 & \\
\hline Medium & 148 & 38.3 & 55 & 37.2 & 93 & 62.8 & \\
\hline Highest level & 68 & 17.6 & 22 & 32.4 & 46 & 67.8 & \\
\hline \multicolumn{7}{|c|}{ Form of discrimination that most impacted life } & 0.02 \\
\hline Not discriminated against & 154 & 39 & 49 & 31.8 & 105 & 68.2 & \\
\hline Race & 52 & 13.2 & 15 & 28.9 & 37 & 71.2 & \\
\hline Language & 101 & 25.6 & 51 & 50.5 & 50 & 49.5 & \\
\hline Immigrant status & 65 & 16.5 & 27 & 41.5 & 38 & 58.5 & \\
\hline Other & 23 & 5.8 & 7 & 30.4 & 16 & 69.6 & \\
\hline \multicolumn{7}{|c|}{ Problems $\mathrm{b} / \mathrm{c}$ foreign born in past 6 months } & 0.08 \\
\hline No & 327 & 81.8 & 116 & 35.5 & 211 & 64.5 & \\
\hline Yes & 73 & 18.3 & 34 & 46.6 & 39 & 53.4 & \\
\hline
\end{tabular}

Table 4 Final stepwise regression model for association between frequency of $>2$ PPR and living with children, food insufficiency and discrimination $^{\mathrm{a}}(N=276)$

\begin{tabular}{|c|c|c|c|}
\hline Likelihood of crowding & OR & $95 \% \mathrm{CI}$ & Wald $P$-value \\
\hline \multicolumn{3}{|l|}{ Live with own children } & $<0.01$ \\
\hline No & 1.0 & - & \\
\hline Yes & 2.3 & $1.4-3.9$ & \\
\hline \multicolumn{3}{|c|}{ Food insufficiency in last 6 months } & 0.02 \\
\hline No & 1.0 & - & \\
\hline Yes & 2.0 & $1.1-3.6$ & \\
\hline \multicolumn{3}{|c|}{ Form of discrimination that most affected life } & 0.04 \\
\hline Not discriminated against & 1.0 & - & \\
\hline Race & 0.6 & $0.3-1.5$ & 0.05 \\
\hline Language & 2.3 & $1.2-4.4$ & 0.02 \\
\hline Immigrant status & 1.2 & $0.6-2.6$ & 0.9 \\
\hline Other & 1.7 & $0.5-5.4$ & 0.5 \\
\hline
\end{tabular}

${ }^{\text {a }}$ Included variables with $P \leq 0.1$ in bivariate table

\section{Discussion}

Undocumented Mexican immigrants in NYC experience extremely high household density: $82.5 \%$ of the sample population lived with more than 1 PPR, and $37.6 \%$ lived with more than 2 PPR. We found the likelihood of higher household density to be associated with food insufficiency, language discrimination, and the presence of one's children in the home. These correlates, coupled with low income and lack of legal immigrant status, suggest that this group faces multiple barriers to health and well-being.

Household density in this sample is many times greater than national and New York City levels. Nation-wide, $2.4 \%$ of households had more than 1 PPR in 2005, a figure that has held relatively steady for the past 20 years [29]. This figure is much higher among foreign-born households in the United States, of which $15.2 \%$ had more than 1 PPR [14]. The high household density in this sample can in part be understood within the context of other characteristics of the sample shown elsewhere to be associated with higher levels of household density-being Mexican-born, primarily young and recent immigrants, and living in NYC. Among all ethnic groups, Mexican-born householders live in the densest conditions-28.2\% of Mexican-born U.S. residents lived with more than 1 PPR in 2001, compared to 11.9\% of other Latin Americans and 9\% of Asians [14]. Younger people and more recent immigrants have also been shown to live in denser conditions [10].

Being renters, and living in NYC appear to further contribute to household density-nation-wide $5 \%$ of 
renters live with more than 1 PPR, and in NYC that increases to $11.2 \%$ [41, 42]. High housing costs and low vacancy rates in NYC most likely lead to greater numbers of people residing in smaller apartments. Additionally, the Mexican population in NYC is newer and less established than other immigrant groups in the city or the Mexicanborn elsewhere in the United States. Newly arrived immigrants often depend on social networks for housing and other resources and support [43-45], but if those networks are also relatively new, resources may be limited. Undocumented immigrants are not eligible for public housing programs or subsidies, and they may also have limited access to credit, references, or formal employment arrangements that are often necessary to apply for private housing, thus limiting their housing options.

Language discrimination as the form of discrimination that most impacted one's life was associated with more than 2 PPR. In NYC in 2000, 23.7\% of the population was not English proficient [19]. A number of studies have pointed to English proficiency and language discrimination as barriers to homeownership and housing access among immigrants [46-49]. As almost $57 \%$ of study participants indicated low or moderate linguistic acculturation, low English proficiency may be an additional barrier to housing, and discrimination may have been perceived more strongly by those who experienced limitations in housing or employment options. Education may also factor into housing options: another study among foreign-born renters in NYC found not having a post-secondary education to be associated with greater household density [12]. In our sample, while a greater percentage of respondents who completed or attended some high school live in conditions of $>2$ PPR compared to those without secondary schooling ( $38.3 \%$ vs. $46.3 \%$ ), this is not the case for those with at least some college, who tended to live in less dense conditions ( $17.2 \%>2$ PPR).

The prevalence of food insufficiency in this sample is almost ten times higher than the USDA's national prevalence estimates of "food insecurity with hunger," a similar measure of periods of not enough nutritional intake (28\% vs. 3-4\%) [50], and consistent with estimates recorded among legal immigrants and Hispanics [51-54]. This population could be at high risk for related negative health outcomes, including poor physical and mental health, particularly among women and children [37, 55-57]. The association of food insufficiency with higher household density among households that include children, and a higher proportion of women who live with more than 2 PPR suggest that these problems may disproportionately affect women and children. An array of health risks for children have been associated with high household density [58-60], but causal relationships are unclear precisely because of compounding factors like food insufficiency among low income populations.
This study is limited in several ways that should be acknowledged. First among them is the difficulty in capturing an accurate measure of household density. Methods vary widely, and while our calculation of PPR is among the most common, it is far from comprehensive, as both people and rooms have dimensions beyond simple numerical counts. We had no measure of space (e.g., square footage), which would account for variations in size of homes with the same number of rooms. Additionally, we lacked information on the composition of households besides the presence of children. For instance, the age of the children could be important to consider, as the impact of infants and toddlers may differ from that of older children and teenagers. Likewise, the relationships between cohabitants (e.g., partners or siblings) were not recorded, nor was any measure of perceived crowding. However, our calculation of PPR provides a rough measure of the household density of the sample, allowing not only comparison within our sample but also with other populations.

Second, we used venue-based sampling and were unable to calculate a response rate. Potential participants' fear or discomfort divulging personal information, particularly about legal status, precluded collection of demographic data or determination of eligibility among non-respondents. We identified diverse venues using qualitative and quantitative information, but it is impossible to assess whether this method resulted in a representative sample of all undocumented Mexican immigrants living in NYC because limited information is available on the properties of the sampling frame (i.e., all undocumented Mexican immigrants in NYC) itself. However, as described elsewhere, our sampling method may have provided a more representative sample than alternative recruiting methods might have. The fact that $85 \%$ of persons recruited for this study were indeed undocumented immigrants suggests that we were successful in identifying areas where undocumented immigrants congregated and in recruiting undocumented immigrants to participate in this study. Furthermore, the demographic profile of our sample is consistent with what is known about undocumented Mexican immigrants living in NYC $[19,20]$.

Third, it is possible that undocumented immigrants may underreport key areas of concern, among them legal status and our key variables, food insecurity and language discrimination. In anticipation of this possibility, we used in-person anonymous interviews that in past research have been proven to be an effective approach to establishing the trust necessary to elicit accurate responses to inquiries about sensitive topics, such as legal status [61]. And finally, the cross-sectional design of our survey does not capture temporal changes in household density such as age and legal status changes.

Despite these limitations, it is clear that undocumented Mexicans live in much denser conditions than other U.S. 
residents. Future studies should investigate the ways in which household density impacts-either negatively or positively - on physical and mental health. The debate around the causal relationship between density and health also calls for a closer look at perceptions of 'overcrowding,' particularly for immigrant groups that may have experienced housing situations in their home countries that varied greatly from U.S. norms. Even as the effects on health of household density are uncertain, density may be an indicator of other more severe housing problems of affordability and quality [62]. Any response to the housing needs of undocumented immigrants should also consider their access to other basic necessities, particularly food and language services. As crossing the border becomes more difficult and more undocumented immigrants remain in the United States and form families here, housing problems are likely to become more severe among this population. Barring radical policy changes, the exclusion of undocumented immigrants from government subsidies and services puts responsibility on local communities to creatively respond to the housing needs of newly arrived immigrants.

Acknowledgements The authors would like to acknowledge the work done by Jerry Lopez, Stacey Strongarone, and Jennifer Ahern in establishing this study. We recognize the generous support of the National Institutes of Health, grant \# DA 017642.

\section{References}

1. Krieger J, Higgins DL. Housing and health: time again for public health action. Am J Public Health. 2002;92(5):758-68.

2. Shaw M. Housing and public health. Annu Rev Public Health. 2004;25:397-418.

3. Evans GW, Kantrowitz E. Socioeconomic status and health: the potential role of environmental risk exposure. Annu Rev Public Health. 2002;23:303-31.

4. Clauson-Kaas J, Dzikus A, Surjadi C, Jensen H, Hojlyng N, Aaby $\mathrm{P}$, et al. Crowding and health in low-income settlements. Avebury, England: United Nations Centre for Human Settlements (Habitat); 1997.

5. Stein L. A study of respiratory tuberculosis in relation to housing conditions in Edinburgh. I. The pre-war period. Br J Soc Med. 1950;4(3):143-69.

6. Al-Khatib IA, Arafat RN, Musmar M. Housing environment and women's health in a Palestinian refugee camp. Int J Environ Health Res. 2005;15(3):181-91.

7. Clark M, Riben P, Nowgesic E. The association of housing density, isolation and tuberculosis in Canadian First Nations communities. Int J Epidemiol. 2002;31(5):940-5.

8. Fuller-Thomson E, Hulchanski JD, Hwang S. The housing/health relationship: what do we know? Rev Environ Health. 2000;15 (1-2):109-33.

9. Gray A. Definitions of crowding and the effects of crowding on health: a literature review. Wellington, New Zealand: New Zealand Ministry of Social Policy; 2001.

10. Myers D, Baer W, Choi S. The changing problem of overcrowded housing. J Am Plan Assoc. 1996;62(1):66-84.
11. Mitchell RB. Cultural and health influences on building, housing and community standards: cost implications for the human habitat. Human Ecol. 1976;4(4):297-330.

12. Schill M, Friedman S, Rosenbaum E. The housing conditions of immigrants in New York City. J Housing Res. 1998;9(2):201-35.

13. Krivo LJ. Immigrant characteristics and Hispanic-Anglo housing inequality. Demography. 1995;32(4):599-615.

14. Lipman B. America's newest working families: Cost, crowding and conditions for immigrants. New Century Housing 2003;4(3).

15. Malone N, Baluja KF, Costanzo JM, Davis CJ. The foreign born population: 2000. Washington, DC: US Census Bureau; 2003.

16. Passel J, Van Hook J, Bean F. Demographic profile of unauthorized migrants and other immigrants, based on Census 2000: characteristics and methods. Washington, DC: Urban Institute; 2005.

17. Passel J. The size and characteristics of the unauthorized migrant population in the U.S.: estimates based on the March 2005 Current Population Survey. Washington, DC: Pew Hispanic Center; 2006.

18. New York City Department of City Planning: Place of birth for the foreign-born population: U.S. Census Bureau 2006 American Community Survey, New York City: New York City Department of City Planning, Population Division; 2007.

19. New York City Department of City Planning: The Newest New Yorkers 2000: New York City Department of City Planning, Population Division; 2004.

20. Rivera-Batiz FL. The State of Newyorktitlan: a socioeconomic profile of Mexican New Yorkers. New York: Teacher's College, Columbia University; 2003.

21. NYC Rent Guidelines Board: 2005 Housing supply report. New York; 2005.

22. Housing NYC: Rents, markets and trends 2005: NYC Rent Guidelines Board; 2005.

23. Hadley C, Galea S, Nandi V, Nandi A, Lopez G, Strongarone S, et al. Hunger and health among undocumented Mexican migrants in a US urban area. Public Health Nutr. 2008;11(2):151-8.

24. Marshall KJ, Urrutia-Rojas X, Mas FS, Coggin C. Health status and access to health care of documented and undocumented immigrant Latino women. Health Care Women Int. 2005;26(10): 916-36.

25. Chavez LR, Cornelius WA, Jones OW. Utilization of health services by Mexican immigrant women in San Diego. Women Health. 1986;11(2):3-20.

26. Loue S, Faust M, Bunce A. The effect of immigration and welfare reform legislation on immigrants' access to health care, Cuyahoga, and Lorain Counties. J Immigr Health. 2000;2(1):23-30.

27. Anthony J, Vlahov D, Celentano D, et al. Self-report interview data for a study of HIV-1 infection among intravenous drug users: description of methods and preliminary evidence on validity. $\mathbf{J}$ Drug Issue. 1991;21:735-753.

28. Vlahov D, Anthony JC, Munoz A, Margolick J, Nelson KE, Celentano DD, et al. The ALIVE study, a longitudinal study of HIV-1 infection in intravenous drug users: description of methods and characteristics of participants. NIDA Res Monogr. 1991;109: $75-100$.

29. Blake K, Kellerson R, Simic A. Measuring overcrowding in housing. Washington, DC: U.S. Department of Housing and Urban Development; 2007.

30. Centers for Disease Control. Measuring healthy days. Atlanta, GA: CDC; 2000.

31. Hennessy CH, Moriarty DG, Zack MM, Scherr PA, Brackbill R. Measuring health-related quality of life for public health surveillance. Public Health Rep. 1994;109(5):665-72.

32. Verbrugge LM, Merrill SS, Liu X. Measuring disability with parsimony. Disabil Rehabil. 1999;21(5-6):295-306.

33. Frongillo E. Validation of measures of food insecurity and hunger. J Nutr. 1999;129(2):506S-509S. 
34. National Research Council. Food insecurity and hunger in the United States: an assessment of the measure. Washington, DC: National Academy of Sciences; 2006.

35. Alaimo K, Olson C, Frongillo E. Low family income and food insufficiency in relation to overweight in US children: is there a paradox? Arch Pediatr Adolesc Med. 2001;155(10):1161-1167.

36. Alaimo K, Olson C, Frongillo E. Family food insufficiency, but not low family income, is positively associated with dysthymia and suicide symptoms in adolescents. J Nutr. 2002;132(4):719-725.

37. Siefert K, Heflin CM, Corcoran ME, Williams DR. Food insufficiency and physical and mental health in a longitudinal survey of welfare recipients. J Health Soc Behav. 2004;45(2):171-86.

38. Marin G, Sabogal F, Marin BVO, Otero-Sabogal R, Perez-Stable EJ. Development of a short acculturation scale for Hispanics. Hispanic J Behav Sci. 1987;9:183-205.

39. Sherbourne CD, Stewart AL. The MOS social support survey. Soc Sci Med. 1991;32(6):705-14.

40. SAS. 9.1 ed. Cary, NC: SAS Institute Inc; 2002.

41. Lee M. Selected findings of the 2002 New York City Housing and Vacancy Survey. New York City: City Department of Housing Preservation and Development; 2003.

42. U.S. Department of Housing and Urban Development: Affordable housing needs: a report to Congress on the significant need for housing; 2003.

43. Massey D, Alarcon R, Durand J, Gonzalez H. Return to Aztlan: the social process of international migration from Western Mexico. Berkeley: University of California Press; 1987.

44. Portes A. Economic sociology and the sociology of immigration: a conceptual overview. In: Portes A, editor. The economic sociology of immigration: essays on networks, ethnicity, and entrepreneurship. New York: Russell Sage Foundation; 1995. p. 1-41.

45. Garcia C. Buscando Trabajo: social networking among immigrants from Mexico to the United States. Hispanic J Behav Sci. 2005;27(1):3-22.

46. Davila A, Mendez R, Mora MT. Are Hispanic immigrants in English-only states at a homeownership disadvantage? Evidence from the 1980 and 1990 U.S. Censuses. Growth Change. 2003; 34(1):40-63.

47. Dion KL. Immigrants' perceptions of housing discrimination in Toronto: the Housing New Canadians Project. J Social Issue. 2001;57(3):523.

48. Myers D, Seong Woo L. Immigrant trajectories into homeownership: a temporal analysis of residential assimilation. Intl Migr Rev. 1998;32(3):593-625.
49. South SJ, Crowder K, Chavez E. Geographic mobility and spatial assimilation among U.S. Latino immigrants. Intl Migr Rev. 2005;39(3):577-607.

50. Nord M, Andrews M, Carlson S. Household food security in the United States, 2004. Washington, DC: U.S. Department of Agriculture, Economic Research Service; 2005.

51. Kasper J. Hungry at home: a study of food insecurity and hunger among legal immigrants in the United States. Boston, MA: Physicians for Human Rights; 2000.

52. Himmelgreen D, Pérez-Escamilla R, Segura-Millán P, Gonzalez A, Singer M, Ferris A. Food insecurity among low-income Hispanics in Hartford, Connecticut: implications for public health policy. Human Org. 2000;59(3):334-342.

53. Kaiser LL, Melgar-Quiñonez H, Townsend MS, Nicholson Y, Fujii ML, Martin AC, et al. Food insecurity and food supplies in Latino households with young children. J Nutr Educ Behav. 2003; 35(3):148-53.

54. Hadley C, Sellen D. Food security and child hunger among recently resettled Liberian refugees and asylum seekers: a pilot study. J Immigr Minor Health. 2006;8(4):369-75.

55. Townsend MS, Peerson J, Love B, Achterberg C, Murphy SP. Food insecurity is positively related to overweight in women. $\mathrm{J}$ Nutr. 2001;131(6): 1738-45.

56. Weinreb L, Wehler C, Perloff J, Scott R, Hosmer D, Sagor L, et al. Hunger: its impact on children's health and mental health. Pediatrics. 2002;110(4):e41.

57. Dubois L, Farmer A, Girard M, Porcherie M. Family food insufficiency is related to overweight among preschoolers. Soc Sci Med. 2006;63(6):1503-16.

58. Alwash R, McCarthy M. Accidents in the home among children under 5: ethnic differences or social disadvantage? Br Med J (Clin Res Ed). 1988;296(6634):1450-3.

59. Shah SM, Selwyn BJ, Luby S, Merchant A, Bano R. Prevalence and correlates of stunting among children in rural Pakistan. Pediatr Int. 2003;45(1):49-53.

60. Murtagh P, Cerqueiro C, Halac A, Avila M, Salomon H, Weissenbacher M. Acute lower respiratory infection in Argentinian children: a 40 month clinical and epidemiological study. Pediatr Pulmonol. 1993;16(1):1-8.

61. Berk M, Schur C, Chavez L, Frankel M. Health care use among undocumented Latino immigrants. Health Affairs. 2000;19:51-64.

62. Dolbeare C. Housing affordability: challenge and context. Cityscape: J Policy Dev Res. 2001;5(2):111-30. 